\title{
A EVOLUÇÃO DA INCLUSÃO DOS ASPECTOS SOCIAIS DA SUSTENTABILIDADE NO LIVRE-COMÉRCIO INTERNACIONAL
}

\author{
Izabel Rigo Portocarrero ${ }^{1}$ \\ Pamela De Almeida Araújo ${ }^{2}$
}

Resumo: O crescimento econômico, por si só, não é suficiente para a melhoria da vida das pessoas e do planeta. Por esta razão, observa-se um esforço mundial na criação de agendas visando um desenvolvimento que prismem o equilíbrio entre os pilares econômico, ambiental e social. Nesse sentido, as relações comerciais internacionais assumem um importante protagonismo. O presente artigo centra-se na evolução das decisões adotadas pelo Órgão de Solução de Controvérsias da OMC (Organização Mundial do Comércio), e objetiva apresentar a inclusão dos aspectos sociais da sustentabilidade no livre comércio internacional. O método é hipotético indutivo, baseado numa ampla revisão bibliográfica.

Palavras-chave: Desenvolvimento; Sustentabilidade Social; Comércio Internacional; OMC; Governança Social.

\section{THE EVOLUTION OF THE INCLUSION OF THE SOCIAL ASPECTS OF SUSTAINABILITY IN THE INTERNATIONAL FREE TRADE}

\begin{abstract}
The economic growth, by itself, is not sufficient to the improvement of planet and people's lives. For this, it can be observed a world effort in the creation of agendas aiming a development that balances economic, environmental and social pillars. In this sense, the international trade relations assume an important prominence. The present article focuses in the evolution of the decisions adopted by the Controversy Solutions Organ of WTO (World Trade Organization), and aims to present the inclusion of the social aspects of sustainability in the international free trade. The method is hypothetical inductive, based in a wide bibliographic review.
\end{abstract}

Keywords: Development; Social Sustainability; International Trade; WTO; Social Governance.

\footnotetext{
${ }^{1}$ Doutora em Direito pela Universidade de Salamanca (2017). Professora de Direito Internacional Privado na Universidade Internacional de Valência. Email: izabelrigo@gmail.com

${ }^{2}$ Mestranda do Programa de Pós Graduação em Direito da Universidade de Passo Fundo-RS (2018), com ênfase na linha de pesquisa Jurisdição Constitucional, Integrante do Grupo de Pesquisa Dimensões do Poder, Gênero e Diversidade e do Grupo Direitos Humanos e Democracia na América Latina, Bolsista Capes. Email: pam.ufg@gmail.com
} 


\section{INTRODUÇÃO}

A OMC (Organização Mundial do Comércio) constituiu-se em 1994, com a firma do Acordo de Marraqueche, a partir do antigo Acordo Geral de Tarifas e Comércio de 1947, o GATT, originado do inglês General Agreementon Tariffs and Trade. Trata-se da instituição responsável pela implantação e supervisão das regras do comércio internacional. Com personalidade jurídica própria, esta organização instituiu uma base jurídica sólida para o sistema multilateral de comércio, com a extinção de derrogações históricas ao comércio entre países, a obrigatoriedade de subscrição dos acordos internacionais entabulados e a instituição de um mecanismo compulsório de solução de controvérsias (PIFFER, 2011, p. 111).

Nos termos do Acordo de Marraqueche, a OMC, além de contar com o apoio de grupos de trabalho especializados organizados na forma de Comitês, é composta de seis órgãos principais, a saber: Conferência Ministerial; Conselho Geral; Órgão de Solução de Controvérsias; Órgão de Revisão de Política Comercial; Conselhos para Bens, Serviços e Propriedade Intelectual; e Secretariado.

Para o estudo proposto neste artigo, nos centraremos no Órgão de Solução de Controvérsias, considerado, segundo Thorstensen e Oliveira $(2014$, p.11) como "a jóia da coroa da OMC". Atualmente o Órgão de Solução de Controvérsias representa o mecanismo de solução de conflitos mais eficaz no âmbito internacional, com um sistema de regras e procedimentos consolidados para dirimir os antagonismos entre os membros, além da possibilidade de estabelecer Painéis cujas decisões podem ser revisadas por um Órgão de Apelação.

Observe-se que o Acordo Constitutivo da OMC determina a exclusividade do Órgão de Solução de Controvérsias para resolver conflitos envolvendo os acordos da organização, eliminando desta forma a possibilidade de que um membro possa impor sanções unilaterais em matéria comercial sem que a controvérsia tenha sido previamente avaliada (BARRAL, 2004, p. 15). Portanto, trata-se de um sistema independente e de natureza sui generis, que possui características de arbitragem, na medida em que um Painel é estabelecido ad hoc. Ademais, quando se constitui um Painel, as partes podem apresentar seus argumentos de forma oral e escrita, abrindo-se a possibilidade de intervenção a terceiros países.

De acordo com Thorstensen (2001, p. 371), “o Órgão de Solução de Controvérsias confere à OMC o poder de impor decisões e permitir a aplicação de retaliações aos membros que mantenham medidas incompatíveis com os acordos da organização.” Tal retaliação, por

Rev. de Direito, Economia e Desenvolvimento Sustentável| e-ISSN: 2526-0057| Porto Alegre | v. 4 | n. 2 | p. 76 - 92 | Jul/Dez. 
exemplo, pode ser realizada através do aumento de tarifas para os bens exportados pelo membro infrator, em um valor equivalente ao das perdas incorridas.

Entretanto, é preciso saber que a mera leitura das regras ou procedimentos, por si só, não é o suficiente para entender o sistema multilateral de comércio internacional, mas é preciso unir e compreender as duas linguagens "a da criação das regras e a do contencioso baseado nessas regras. Em suma a compreensão das ligações, entre a área da negociação [...] e a de supervisão e cumprimento (enforcement) de tais regras [...]” (THORSTENSEN e OLIVEIRA, 2014, p.11). Nessa perspectiva é que será analisada a relação entre o comércio internacional e os aspectos sociais da sustentabilidade de forma a evidenciar sua evolução dentro do sistema multilateral de comércio, com enfoque principal na posição adotada pelo Órgão de Solução de Controvérsias da OMC.

Para realizar a análise proposta, o presente artigo divide-se em cinco partes: uma pequena noção introdutória; uma apresentação da inclusão dos aspectos sociais da sustentabilidade entre as exceções previstas no artigo XX do GATT; uma abordagem exemplificativa sobre como algumas questões comerciais com efeitos sociais transfronteiriços foram decididas pelos órgãos de resolução de controvérsias no sistema multilateral de comércio; uma revisão sintética das exceções relativas à segurança do artigo XXI do GATT e da discussão relativa à proteção dos trabalhadores nas rodadas de negociação; e, finalmente, uma conclusão sobre o tema, mediante a qual se demonstra que a OMC tem caminhado paulatinamente na direção de um contínuo balanceamento na ponderação entre as regras de livre-comércio e os aspectos sociais da sustentabilidade.

\section{OS ASPECTOS SOCIAIS DA SUSTENTABILIDADE E OS ACORDOS DA ORGANIZAÇÃO MUNDIAL DO COMÉRCIO}

O desenvolvimento que antes era visto como sinônimo de crescimento econômico acabou por não refletir em melhoria ou a qualidade de vida para todos. Esse tipo de desenvolvimento visto de forma míope ou reduzida, em que as visões centram atenção apenas na renda per capita, e cujos benefícios não chegam a todos, levou a necessidade de refletir sobre a natureza do desenvolvimento que se buscava.

Desde os anos 70, o conceito de desenvolvimento passou por uma ampla reconceitualização, partindo da busca por uma forma de desenvolvimento que não agredisse o

Rev. de Direito, Economia e Desenvolvimento Sustentável| e-ISSN: 2526-0057| Porto Alegre | v. 4 | n. 2 | p. 76 - 92 | Jul/Dez. 
meio ambiente que inicialmente denominou-se ecodesenvolvimento. Tal idéia foi lançada em 1972, durante a Conferência das Nações Unidas sobre o Meio Ambiente, na cidade de Estocolmo e avançou no sentido de criar o conceito que hoje conhecemos como “desenvolvimento sustentável” (SACHS, 2004, p.36). Dos anos 1970 até o acontecimento da Cúpula sobre Desenvolvimento Sustentável realizada em Joanesburgo, em 2002, o conceito de desenvolvimento sustentável foi "refinado", contudo segundo Sachs, atualmente o desenvolvimento sustentável:

\footnotetext{
[...] obedece ao duplo imperativo ético da solidariedade com as gerações presentes e futuras, e exige a explicitação de critérios de sustentabilidades social e ambiental e de viabilidade econômica. Estritamente falando, apenas as soluções que considerem estes três elementos, isto é, que promovam o crescimento econômico com impactos positivos em termos sociais e ambientais, merecem a denominação de desenvolvimento [...] (SANCHS, 2004, p.36)
}

Nesse contexto, a sustentabilidade social é um componente, segundo Sachs (2004, p.36), "essencial” do conceito de desenvolvimento sustentável. Demonstrando, ainda o autor, que o crescimento econômico deveria possuir impactos positivos não só em termos ambientais, mas também em termos sociais, de tal modo que o crescimento econômico não fosse reduzido apenas ao PIB (produto interno bruto), mas também refletisse na geração de empregos, no auxílio da redução da pobreza e das desigualdades (SACHS, 2004, p.36-37).

Para Amartya Sen (2013, p.10) o “desenvolvimento consiste na eliminação de privações de liberdades que limitam escolhas e oportunidades das pessoas de exercer ponderadamente sua condição de agente". Nesse sentido é que segundo Sachs (2004, p.36) o conceito de desenvolvimento ganha uma nova definição "em termos de universalização e do exercício efetivo de todos os direitos humanos: políticos, civis e cívicos; econômicos, sociais, culturais; bem como direitos coletivos ao desenvolvimento, ao ambiente".

$\mathrm{Na}$ declaração do acordo constitutivo da OMC se destaca o reconhecimento pelos membros de que as suas relações na esfera da atividade comercial e econômica devem objetivar a "elevação dos níveis de vida", o "pleno emprego" e o "aumento da produção e do comércio de bens e de Serviços", e ao mesmo tempo, a "utilização ótima dos recursos mundiais em conformidade com o objetivo de um desenvolvimento sustentável” e, por fim, buscando "proteger e preservar o meio ambiente" criando meios para isso.

Nesse sentido, as controvérsias relacionadas com os aspectos sociais da sustentabilidade têm sido decididas no âmbito da OMC a partir da interpretação das restrições 
comerciais estabelecidas no artigo XX, alíneas "b" e "g", do GATT, que reconhecem o equilíbrio entre a necessidade de eliminação das barreiras alfandegárias e a liberdade concedida pelos países membros para tomar decisões que protejam interesses sensíveis à população nacional, permitindo a restrição ao livre-comércio em alguns casos, senão vejamos:

\footnotetext{
ARTIGO XX - EXCEÇÕES GERAIS. Desde que essas medidas não sejam aplicadas de forma a constituir quer um meio de discriminação arbitrária, ou injustificada, entre os países onde existem as mesmas condições, quer uma restrição disfarçada ao comércio internacional, disposição alguma do presente capítulo será interpretada como impedindo a adoção ou aplicação, por qualquer Parte Contratante, das medidas: a) necessárias à proteção da moralidade pública; b) necessárias à proteção da saúde e da vida das pessoas e dos animais e à preservação dos vegetais;
}

Por força deste artigo, medidas de restrição ao comércio podem ser tomadas para proteger, por exemplo, a saúde e a vida dos seres humanos e a moralidade pública. A função desse dispositivo normativo é favorecer o diálogo com os demais subsistemas do direito internacional, notadamente os afetos à seara dos Direitos Humanos. Por meio dele, então, estabelece-se a primazia de medidas destinadas a proteger a vida e saúde, assim como a proteção da moralidade pública mesmo que restritivas ao comércio, elencando-se como exceções às regras sobre a liberalização comercial "com o intuito de permitir a execução de políticas governamentais que promovam a realização de finalidades essenciais para as sociedades domésticas" (AMARAL JUNIOR, 2008, p. 191).

No entanto, essa disposição normativa possui alguns termos dúbios que deixam margem a distintas interpretações e que, portanto, tem sido objeto de interpretação pelo Órgão de Solução de Controvérsias da OMC em litígios centrados principalmente nos limites e na amplitude de conceitos como "moralidade pública", e nos critérios necessários para que uma medida de exceção seja considerada "arbitrária ou injustificável", ou apenas uma restrição "disfarçada" ao livre-comércio, em franca violação ao "princípio da não-discriminação" entre os membros da OMC (expresso nas cláusulas da "nação mais favorecida", artigo I do GATT, e do "tratamento nacional", artigo III do GATT) tornando-se inegável o possível conflito entre esses tratados e os acordos da organização.

Dentre os casos analisados pelo Órgão de Solução de Controvérsias a partir dos quais é possível afirmar que a OMC passou a desempenhar um importante papel na governança social, destacam-se os seguintes.

Rev. de Direito, Economia e Desenvolvimento Sustentável| e-ISSN: 2526-0057| Porto Alegre | v. 4 | n. 2 | p. 76 - 92 | Jul/Dez. 


\section{1 "Caso Amianto" de 1998 (DS135), envolvendo a Comunidade Europeia e o Canadá}

Refere-se à reclamação do Canadá diante da proibição imposta por um país da Comunidade Europeia, França, sobre a sua importação de amianto e de produtos que o contenham, considerando-o uma substância altamente tóxica cuja exposição pode causar graves riscos para a saúde humana, como o câncer de pulmão, por exemplo. Nesse caso, o referido país da Comunidade Europeia impôs a proibição de sua importação alegando como justificativa para a adoção da medida o controle dos riscos à saúde ocasionados por essa substância. Diante disso, o Canadá, segundo maior produtor de amianto no mundo, impugnou a proibição junto à OMC, aduzindo que a medida adotada pelo governo Francês infringia as regras atinentes ao livrecomércio.

O Painel instaurado no âmbito da OMC, ao analisar os riscos gerados pelo aludido produto à saúde humana e ao meio ambiente, decidiu em favor da Comunidade Europeia. Esta decisão se confirmou em sede de Apelação, considerando-se a medida como necessária para "proteger a saúde e a vida das pessoas e dos animais ou para preservar as plantas", nos termos da alínea "b" do artigo XX. Trata-se de um caso relevante porque, pela primeira vez, o Órgão de Solução de Diferenças aceitou a implementação de uma medida restritiva ao comercio internacional para proteger a vida e a saúde humana (RAUCCI, 2010, p. 67).

\section{2 “Caso dos Pneus Recauchutados" de 2005 (DS332), envolvendo o Brasil e a Comunidade Europeia}

Neste caso, a Comunidade Europeia (CE) atacou a proibição da importação de pneus recauchutados no Brasil, com base principalmente na exceção que este país fazia aos produtos com as mesmas características provenientes do Mercado Comum do Sul (MERCOSUL), bem como aos produtos importados mediante autorização judicial. Portanto, a alegação da Comunidade Europeia consistia em que havia uma discriminação injustificável no comércio entre membros, causando uma clara ofensa à cláusula de tratamento nacional, prevista no artigo III do GATT.

O estabelecimento do Painel ocorreu em 17 de novembro de 2005. Em sede de defesa, o Brasil centrou-se na exceção prevista no artigo XX, alínea "b", do GATT, aduzindo que as medidas adotadas pelo governo Brasileiro no tocante aos pneus recauchutados derivavam da ratificação da "Convenção da Basiléia de 1989 sobre o Controle de Movimentos

Rev. de Direito, Economia e Desenvolvimento Sustentável| e-ISSN: 2526-0057| Porto Alegre | v. 4 | n. 2 | p. 76 - 92 | Jul/Dez. 
Transfronteiriços de Resíduos Perigosos e seu Depósito”. Em sua argumentação, declara que o descarte indevido de pneus, com seu lançamento em terrenos abandonados ou sua queima, provoca inevitáveis danos à fauna e à flora, estando ainda diretamente relacionado com a proliferação de vetores responsáveis por doenças como a dengue, cólera, malária, febre amarela, entre outras. Reiterando que a proibição da importação de pneus reformados era necessária para se atingir os fins pretendidos, sinaliza que esse descarte poderia ocasionar incêndios, com a consequente liberação de gases tóxicos lesivos à saúde humana e o meio ambiente (RAUCCI, 2010, p. 91).

Por um lado, o Painel acolheu o argumento da Comunidade Europeia de que a autorização judicial para a importação de pneus recauchutados de países não-integrantes do MERCOSUL prejudicava o alcance do objetivo declarado de defender o meio ambiente e a saúde humana. Por outro lado, desestimou a alegação de que a importação de idênticos produtos de países do MERCOSUL seria discriminatória e injustificável, porque nesse particular o Brasil estava cumprindo uma decisão impositiva do Tribunal Arbitral do MERCOSUL. Desse modo, o Painel decidiu que as medidas atacadas, não sendo discriminatórias em sua gênese, se justificavam provisoriamente sobre a exceção da alínea "b" do artigo XX do GATT (RIBEIRO, 2008, p. 35).

Levada a questão ao Órgão de Apelação, este manteve a decisão do Painel no sentido de ser justificável a medida adotada para fins de proteger a vida e a saúde humana com base no artigo XX, alínea "b”, do GATT. No entanto, declarou que a isenção da proibição de importação de pneus usados dada ao MERCOSUL e as importações por meio de autorizações judiciais, independentemente do volume de importações que propiciavam, configurava uma discriminação injustificada e arbitrária ao comércio internacional (RAUCCI, 2010, p. 93). Como resultado do contencioso, o Órgão permitiu que, mediante adaptações e algumas condições, o Brasil mantivesse a medida que proíbe a importação de pneus reformados.

Como afirma Patriota (2013, p. 176), esta controvérsia revela um flagrante exemplo de contradição nos discursos de cooperação ao desenvolvimento, considerando que, ignorando a evidencia científica de que os pneus recauchutados constituem um dos maiores desafios ambientais para as nações, em vista da inexistência de um método de descarte seguro, adequado e economicamente viável para lidar com o grande volume de pneus lançados na natureza, a Comunidade Europeia impugnou a legislação brasileira que proibia as importações desses produtos.

Rev. de Direito, Economia e Desenvolvimento Sustentável| e-ISSN: 2526-0057| Porto Alegre | v. 4 | n. 2 | p. 76 - 92 | Jul/Dez. 
A solução encontrada pela União Europeia (EU) para o lixo gerado nos paísesmembros foi exportá-lo para os países em desenvolvimento e caracterizar de protecionismo os esforços legítimos do Brasil de limitar a entrada deste tipo de resíduo no País. O Órgão de Apelação da OMC confirmou o entendimento sobre a necessidade da medida para proteger a saúde humana e o meio ambiente, pois, ao reduzir a geração de resíduos, a medida brasileira combate os riscos associados a sua destruição, acúmulo e transporte, que incluem doenças transmitidas por mosquitos e problemas de saúde ocasionados, entre outras causas, pela contaminação do meio ambiente.

A importância desta controvérsia radica no fato de ter sido o segundo julgamento favorável à saúde humana no âmbito do comercio internacional (REALE, 2010, p. 94). Como consequência dessa decisão, destaca-se também que no âmbito do MERCOSUL, o Brasil conseguiu a edição da resolução GMC 25/08 para criação do Grupo ad hoc para a criação de uma política regional sobre pneus.

\section{3 “Caso Estados Unidos - Jogos de Azar" de 2003 (DS285), envolvendo Antígua e Barbuda e os Estados Unidos}

O Artigo XX, alínea "a” do GATT permite que um Membro adote ou aplique medidas “necessárias para proteger a moral pública". No entanto, até o momento nenhum país tentou justificar uma restrição comercial com base nessa disposição normativa do GATT. A "moral pública" somente foi abordada pelo Órgão de Solução de Controvérsias em 2003, no caso "Estados Unidos - Jogos de Azar", em uma matéria disciplinada pelo Acordo Geral sobre Comércio de Serviços, o GATS (do inglês General Agreementon Trade in Services).

Neste caso, Antígua e Barbuda argumenta que, por efeito acumulativo, as medidas aplicadas por Estados Unidos lhe impediam o fornecimento de serviços transfronteiriço de jogos de azar e apostas, produzindo um efeito de "proibição total". Em resposta, Estados Unidos alegou que esta medida era "necessária" para proteger a moral pública, nos termos da alínea "a" do artigo XIV do GATS, porque se baseava em preocupações legítimas específicas com relação à lavagem de dinheiro, fraude e a saúde de menores relacionados ao fornecimento a distancia de serviços de jogos de azar e apostas.

A este respeito, tanto o Painel quanto o Órgão de Apelação consideraram que a legislação federal dos Estados Unidos que proibia este comercio é "necessária para proteger a moral ou manter a ordem pública”. No entanto, o Órgão de Apelação constatou que os Estados

Rev. de Direito, Economia e Desenvolvimento Sustentável| e-ISSN: 2526-0057| Porto Alegre | v. 4 | n. 2 | p. 76 - 92 | Jul/Dez. 
Unidos não demonstrou que esta proibição se aplicava tanto aos provedores estrangeiros quanto aos nacionais, de modo que a restrição infringia as disposições do Preâmbulo do Artigo XIV do GATS, uma vez que discriminava entre produtos domésticos e importados similares.

O caso é considerado relevante no âmbito do debate entre o comércio e os aspetos sociais da sustentabilidade porque o conceito de moralidade pública alcançou clareza de duas maneiras. Por um lado, estabeleceu-se que o controle da moral pública implica a existência de normas sobre o comportamento correto ou incorreto mantido em nome de uma comunidade ou nação e, por outro lado, vinculou-se este conceito às evoluções e mudanças sociais. Portanto, a diferença abriu um precedente para promover a proteção da moral pública de acordo com as características e valores de cada Membro da OMC.

\section{4 “Caso CE - Hormônios" de 1998(DS26 y DS28), envolvendo Estados Unidos, Canadá e a Comunidade Europeia:}

No caso "CE - Hormoniôs", os Estados Unidos e Canadá alegaram que a proibição imposta pela Comunidade Europeia à carne bovina tratadas com hormônios era incompatível com o Acordo sobre Medidas Sanitárias e Fitossanitárias, o SPS (do inglês Sanitary and Phytosanitary Measures), em particular com seus artigos 2, 3 e 5, com o acordo sobre Barreiras Técnicas ao Comércio, o TBT (do inglês Agreementon Techinical Barriersto Trade) e com o GATT.

Em resposta, o Painel sustentou que, ao manter as medidas sanitárias que não se baseiam em uma avaliação de risco, a Comunidade Europeia havia atuado de forma incompatível com o parágrafo $1^{\circ}$ do Artigo $5^{\circ}$ do Acordo SPS. Na mesma linha, entendeu que a medida adotada representava distinções arbitrárias ou injustificáveis nos níveis de proteção sanitária que considerava adequados em diferentes situações, que tem por resultado uma discriminação ou uma restrição encoberta de comercio internacional. Ademais, entendeu que as medidas sanitárias mantidas pela comunidade não estão baseadas em normas internacionais existentes.

O Órgão de Apelação aceitou que os países poderiam manter o nível de proteção à saúde que consideravam apropriado, mas confirmou, ainda que se baseando em um razoamento modificado, as constatações do Painel. De acordo com este órgão, os estudos científicos apresentados pela Comunidade Europeia nesta controvérsia não eram "o suficientemente específicos com respeito ao assunto de que se trata", porque eram "estudos gerais que mostram,

Rev. de Direito, Economia e Desenvolvimento Sustentável| e-ISSN: 2526-0057| Porto Alegre | v. 4 | n. 2 | p. 76 - 92 | Jul/Dez. 
de fato, a existência de um risco geral de câncer; mas não se concentram no tipo particular de risco que aqui se apresenta, nem tratam deste tipo de risco". Por esta razão, chegou-se à conclusão de que "não se facilitou ao Painel nenhuma avaliação de risco que apoiasse ou justificasse razoavelmente a proibição da importação contida nas Diretivas da Comunidade Europeia".

Como resultado, observa-se que, embora existam interpretações no Órgão de Solução de Controvérsias que favoreçam a defesa dos aspectos sociais da sustentabilidade baseadas na exceção "b" do Artigo XX do GATT, esses precedentes são limitados aos três casos acima descritos, e somente em uma ocasião o resultado foi diretamente favorável à proteção da vida e saúde humana.

\section{EXCEÇões RELATIVAS À SEgURANÇA PREVISTAS NO ARTIGO XXI DO} GATT E A PROTEÇÃO DOS TRABALHADORES NO COMÉRCIO INTERNACIONAL

Existe outra disposição do GATT relevante para a discussão da inclusão dos aspectos sociais da sustentabilidade no sistema multilateral de comércio. Trata-se do artigo XXI, que permite que os Membros adotem medidas para a proteção dos interesses essenciais de sua segurança, bem como para cumprir as obrigações assumidas na Carta das Nações Unidas para a manutenção da paz e segurança internacionais. Ressalte-se que esta disposição não lhes permite adotar restrições comerciais para proteger a segurança dos cidadãos de outro país, a menos que autorizado pelo Conselho de Segurança da ONU (AARONSON, 2007, p.20). De acordo com esta disposição:

\footnotetext{
ARTIGO XXI - EXCEÇÕES RELATIVAS À SEGURANÇA. Nenhuma disposição do presente Acordo será interpretada: (a) como impondo a uma Parte Contratante a obrigação de fornecer informações cuja divulgação seja, a seu critério, contrária aos interesses essenciais de sua segurança; (b) ou como impedindo uma Parte Contratante de tomar todas as medidas que achar necessárias à proteção dos interesses essenciais de sua segurança: (i) relacionando-se às matérias desintegráveis ou às matérias primas que servem à sua fabricação; (ii) relacionando-se ao tráfico de armas, munições e material de guerra e a todo o comércio de outros artigos e materiais destinados direta ou indiretamente a assegurar o aprovisionamento das forças armadas; (iii) aplicadas em tempo de guerra ou em caso de grave tensão internacional; (c) ou como impedindo uma Parte Contratante de tomar medidas destinadas ao cumprimento de suas obrigações em virtude da Carta das Nações Unidas, a fim de manter a paz e a segurança internacionais.
}

Rev. de Direito, Economia e Desenvolvimento Sustentável| e-ISSN: 2526-0057| Porto Alegre | v. 4 | n. 2 | p. 76 - 92 | Jul/Dez. 
Segundo Aaronson (2007, p.20), alguns países contaram com essa disposição para aplicar sanções comerciais contra nações como a África do Sul, Somália, Cuba e Mianmar (Birmânia), que violavam os Direitos Humanos de seu povo. O autor também relata que os Estados Unidos usaram o mesmo preceito contra países produtores de petróleo, como Líbia, Iraque, Irã, Sudão e Síria, com base na alegação de que se tratavam de nações terroristas.

No entanto, curiosamente, em nenhum momento os Membros sancionados questionaram a aplicação do Artigo XXI do GATT. Até certo ponto, conforme sustenta Aaronson (2007, p. 20) isso se deve ao fato de que não existe um interesse real de que o Órgão de Solução de Controvérsias pressione uma mudança de comportamento em relação às violações de Direitos Humanos. Para este fim, o interesse dos membros na inclusão dos aspectos sociais da sustentabilidade no âmbito do sistema multilateral de comércio tem sido objeto de divergência nas rodadas de negociações da OMC, nas quais a proteção do trabalhador recebe atenção especial.

Enquanto os países desenvolvidos defendem uma maior vinculação dos acordos comerciais às obrigações estabelecidas nas Convenções da Organização Internacional do Trabalho (OIT), os países em desenvolvimento se opõem a essa iniciativa, porquanto poderia constituir uma barreira às suas exportações. Portanto, a proteção dos trabalhadores no comércio internacional é controvertida porque envolve dois pontos de vista antagônicos.

De um lado, alguns países em desenvolvimento opõem-se à inclusão dos padrões trabalhistas no comércio, sob o argumento de que a introdução no comércio internacional de temas não relacionados ao intercâmbio de mercadorias afetaria a liberalização e, assim, a promoção da riqueza, com um impacto negativo sobre as exportações. Nesse sentido, a proteção dos trabalhadores seria uma barreira não tarifaria imposta pelos países desenvolvidos às importações dos países em desenvolvimento. Do outro lado, alguns países desenvolvidos, como é o caso dos Estados Unidos, defendem a ideia de que as exportações de bens produzidos em más condições de trabalho é uma forma de competição desleal no comércio. Em síntese, considera-se que a proteção dos trabalhadores implica maiores gastos por parte dos empregadores, o que repercute no preço final do produto (THORSTENSEN, 1998, p. 44).

Outra importante questão que forma parte dessa discussão consiste na viabilidade de introduzir-se a proteção dos trabalhadores nos acordos da OMC. A principal razão é que poderia ocorrer uma sobrecarga no sistema de solução de controvérsias desta organização, transformando-o em um tribunal de cunho mais político e social do que comercial. Em outras 
palavras, questionam-se as vantagens de conferir à OMC potestade para decidir temas não diretamente relacionados com o comércio.

Efetivamente, ainda que a entidade responsável pela proteção dos trabalhadores em âmbito mundial seja a OIT (Organização Internacional do Trabalho), esta não dispõe de um mecanismo de sanção, como é o caso do Órgão de Solução de Controvérsia da OMC, uma vez que se baseia na pressão política internacional contra os membros que desrespeitam as convenções aprovadas. Portanto, diferentemente da OMC, a OIT está baseada na cooperação entre seus membros, e não na coerção.

A proteção dos trabalhadores foi objeto de discussão durante a Rodada de Tóquio e a Rodada Uruguai, com o apoio dos Estados Unidos, Noruega e França. No entanto, em ambas oportunidades o tema foi bloqueado pelos países em desenvolvimento, que argumentavam que padrões trabalhistas eram uma forma de protecionismo que minaria a vantagem comparativa dos seus custos de trabalho (THORSTENSEN, 1998, p. 50). Durante a Conferência Ministerial de Marraqueche, em 1994, que aprovou os resultados da Rodada Uruguai, os Estados Unidos e a França voltaram à carga, pressionados por associações de trabalhadores e organizações não governamentais. Contudo, o tema foi incluído apenas nos comentários finais do relatório do Presidente do Comitê de Negociações de Comércio.

Em dezembro de 1996, na Conferência Ministerial de Singapura, Estados Unidos e Noruega defenderam a inclusão da proteção trabalhista dentro da OMC através da observação de alguns princípios trabalhistas básicos. No entanto, o tema foi novamente repelido pelos países em desenvolvimento, que conseguiram a aprovação de uma declaração específica em que se imputava a responsabilidade de seu tratamento para a Organização Internacional do Trabalho, a OIT. O tema foi incluído na Declaração Final da Conferência nos seguintes termos:

\footnotetext{
"Nós Ministros, renovamos nosso compromisso para o cumprimento de padrões trabalhistas básicos internacionalmente reconhecidos. A OIT é o órgão competente para estabelecer e lidar com tais padrões, e afirmamos nosso apoio pelo seu trabalho em promovê-los. Acreditamos que o crescimento econômico e o desenvolvimento suportados pelo aumento do comércio e a sua liberalização contribuem para a promoção desses padrões. Rejeitamos o uso de padrões trabalhistas com fins protecionistas, e concordamos que a vantagem comparativa dos países, não deve, de maneira alguma, ser colocada em questão. A OMC e a OIT continuarão a sua colaboração mútua."(Declaração Ministerial de Singapura, WT/MIN(96)/DEC, 1996, parágrafo 4)
}

Existem divergências quanto à potestade da OMC para proteger esses direitos. Estas discussões concentram-se principalmente na competência do Órgão de Solução de 
Controvérsias para decidir sobre as violações a regras externas ao sistema de comercial multilateral.

A esse respeito, o Artigo 3.2 do Entendimento sobre Solução de Controvérsias estabelece que a principal função do Órgão de Solução de Controvérsias é esclarecer as disposições do GATT “de acordo com as regras usuais de interpretação do Direito Internacional Público". Estas regras encontram-se reunidas na Convenção de Viena sobre o Direito dos Tratados (ONU, 1980), cujos artigos estabelecem que os tratados serão analisados levando em conta seu texto, o contexto em que foram escritos e os objetivos e finalidades dos mesmos.

Na prática, no caso "Estados Unidos-Camarões" (DS58), o Órgão de Apelação usou certos preceitos do Direito Internacional, como a Convenção sobre Diversidade Biológica, para dar conteúdo ao termo "recurso natural esgotável" do Artigo XX (g) do GATT, o que permitiu que as tartarugas marinhas fossem consideradas um recurso natural não renovável. Nas mesmas circunstâncias, em "CE - Amianto", o órgão contou com várias convenções da Organização Mundial da Saúde (OMS) para encontrar evidências sobre a toxicidade do amianto. Além disso, no caso "CE - Hormônios" levou-se em conta o Codex Alimentarius da FAO, a Organização das Nações Unidas para Alimentação e Agricultura, do inglês Food and Agriculture Organization e da OMS por referência direta ao Acordo sobre Medidas Sanitárias e Fitossanitárias. De acordo com Morosini e Niencheski (2014, p. 157):

\footnotetext{
"Quando as normas da OMC não excluam a aplicação de determinada regra, as demais normas de direito internacional continuam a ser aplicáveis. Através do recurso a regras gerais do direito internacional, restou comprovado que, no silêncio de um acordo da OMC, podem sim ser aplicadas as demais normas do direito internacional. A dizer, Painéis e Órgão de Apelação podem aplicar princípios gerais do direito internacional quando as normas da OMC não vedem expressamente sua aplicação. Afirmar o contrário, que a OMC não pode considerar normas que não estejam expressamente referidas nos seus tratados, é ir contra o princípio básico de que as regras de direito internacional se aplicam incondicionalmente aos tratados."
}

Portanto, no exercício de interpretação das disposições previstas no GATT favoráveis aos aspectos sociais da sustentabilidade, o Órgão de Solução de Controvérsias deve utilizar outras regras de Direito Internacional. Nesse mesmo sentido, afirma Marceau (2002, p.779):

\footnotetext{
“O escopo limitado da Organização Mundial do Comércio não significa que seus Acordos façam parte de um sistema de Direito Internacional hermeticamente fechado e isolado. Pelo contrário, os preceitos do Mecanismo de Solução de Controvérsias exigem que os painéis e o Órgão de Apelação usem ou levem em consideração vários princípios, tratados e costumes relevantes ao interpretar as negociações comerciais, incluindo aquelas relacionadas com os Direitos Humanos."
} 
Conforme sinaliza Thorstensen (1998, p. 51), apesar da oposição dos países em desenvolvimento, existem propostas de introdução da proteção dos trabalhadores nos Acordos da OMC. Nesse sentido, a autora sugere que a ausência de padrões trabalhistas básicos poderia ser considerada como:

\footnotetext{
“a) antidumping: dentro do Artigo VI do GATT 1994, como uma forma de introduzir o produto em um membro, com preços abaixo do valor normal e, assim, de forma considerada desleal; b) anti-subsídio: dentro do Artigo VI e XVI do GATT 1994, como uma forma de subsídio do governo, ao permitir condições trabalhistas em níveis muito baixos; c) exceção às regras gerais: dentro do Artigo XX do GATT 1994, como uma exceção às regras gerais de restrição às importações, a ser incluída nos casos já previstos de proteção à vida humana, animal ou vegetal e segurança; e d) anulação ou prejuízo de benefícios: dentro do Artigo XXIII do GATT 1994, sob a alegação de que os benefícios derivados de uma negociação estão sendo anulados ou prejudicados."
}

No caso da aplicação do Artigo XXIII, os membros deveriam apresentar ao Órgão de Solução de Controvérsias argumentos passíveis de demonstrar que o tratamento diferenciado oferecido aos trabalhadores configuraria um prejuízo aos benefícios derivados de uma negociação. Assim, estabelecer-se-ia um Painel, cuja decisão poderia ser revisada pelo Órgão de Apelação resultando em uma recomendação que, de não ser cumprida, poderia reverter-se em uma retaliação. Esse órgão poderia consultar a OIT durante o processo decisório.

Uma alternativa a ser considerada consiste em conferir maior força coercitiva à OIT. O desafio, nesse caso, seria encontrar um consenso entre os membros para que a organização tivesse capacidade de instaurar um procedimento com contraditório e decisões retaliativas. Evidentemente, o tema está longe de ser esgotado, e depende da proposição de novas iniciativas nos próximos encontros ministeriais e rodadas de negociação da OMC.

\section{CONSIDERAÇÕES FINAIS}

O comércio é condição necessária para o crescimento e o crescimento é fundamental para um desenvolvimento mais inclusivo, sobretudo, quando esse crescimento não é levado em conta isoladamente. Não à toa, o Acordo Constitutivo da OMC alberga no seu preâmbulo aspectos de desenvolvimento, claramente sustentável, já que reconhece que as políticas comerciais dos países membros devem apoiar a elevação dos níveis de vida, o pleno emprego,

Rev. de Direito, Economia e Desenvolvimento Sustentável| e-ISSN: 2526-0057| Porto Alegre | v. 4 | n. 2 | p. 76 - 92 | Jul/Dez. 
produção de bens e serviços de modo a utilizar-se dos recursos mundiais da melhor forma possível.

Não obstante, ainda os termos "moral pública", "vida e saúde humana" ou "paz e segurança internacionais" conformem medidas vinculadas ao aspecto social da sustentabilidade, existem divergências quanto ao alcance das decisões da OMC para proteger esses direitos. Estas discussões concentram-se principalmente na competência do Órgão de Solução de Controvérsias para decidir sobre as violações a regras externas ao sistema de comercial multilateral.

Embora segundo o Artigo 3.2 do Entendimento sobre Solução de Controvérsias dispor que a principal função do Órgão de Solução de Controvérsias seja esclarecer as disposições do GATT nos termos das regras usuais de interpretação do Direito Internacional Público, é imprescindível levar-se em conta o seu texto, bem como, o contexto em que foram escritos e os objetivos e finalidades dos mesmos.

Como vimos, houve situações, como no caso "Estados Unidos - Camarões" (DS58), no "CE - Amianto" e no CE - Hormônios" em que foram levados em conta certos preceitos do Direito Internacional, baseando-se noutras convenções para dar solução ao caso. Por esta razão, existe um entendimento pacificado de que quando as normas da OMC não excluam a aplicação de determinada regra, as demais normas de direito internacional continuam a ser aplicáveis, em consonância com o princípio básico de que as regras de direito internacional se aplicam incondicionalmente aos tratados.

Portanto, no exercício de interpretação das disposições previstas no GATT favoráveis aos aspectos sociais da sustentabilidade, o Órgão de Solução de Controvérsias deve utilizar outras regras de Direito Internacional. Ocorre que a transcendência da proteção dos seres humanos no Órgão de Solução de Controvérsias ainda permanece estrita. Essa limitação devese principalmente ao pequeno número de controvérsias levadas à apreciação deste órgão, coma proposta de uma discussão baseada na sustentabilidade social. Essa aparente falta de interesse resulta também em uma barreira às iniciativas propostas nas rodadas de negociação, que até o momento não se concretizaram em disposições obrigatórias.

Rev. de Direito, Economia e Desenvolvimento Sustentável| e-ISSN: 2526-0057| Porto Alegre | v. 4 | n. 2 | p. 76 - 92 | Jul/Dez. 


\section{REFERÊNCIAS BIBLIOGRÁFICAS}

AARONSON, Susan Ariel. (2007). Seeping in slowly: how human rightsconcerns are penetratingthe WTO. WorldTradeReview. 6(03), 413-449.

BARRAL, Welber. O Comércio Internacional. Belo Horizonte: Del Rey, 2007.

DA VEIGA, José Eli. Desenvolvimento sustentável: o desafio do século XXI. Editora Garamond, 2005.

AMARAL JUNIOR, Alberto do. A solução de controvérsiasna OMC. São Paulo: Atlas, 2008.

MAECEAU, G. (2002). WTO dispute settlement and human rights. EuropeanJournal of International Law. 13(4), 753-814. Disponível em:<http://ejil.org/pdfs/13/4/1561.pdf >Acesso em 04 de set. 2018.

MOROSINI, Fabio Costa; NIENCHESKI, LuísaZuardi. A Relação entre os Tratados MultilateraisAmbientais e os Acordos da OMC: é possível conciliar o conflito?. Revista de $\begin{array}{lllllll}\text { Direito Internacional. } & \text { V. } & 11, & \mathrm{n}^{\circ} & 2, & 2014 . & \text { Disponível }\end{array}$ em:〈https://www.publicacoes.uniceub.br/rdi/article/view/3082/pdf> Acesso em 07 de set. 2018 .

OMC. Brasil - Pneus Recauchutados (2005). DS332: Brasil - Medidas que afetam as importações de pneus recauchutados. Disponível em: <https://www.wto.org/spanish/tratop_s/dispu_s/cases_s/ds332_s.htm>Acesso em 06 de set. 2018.

OMC. CE - Amianto (1998). DS135: Comunidades Européias - Medidas que Afetam Amianto e ProdutosContendo Amianto. Disponível em: <https://www.wto.org/spanish/tratop_s/dispu_s/cases_s/ds135_s.htm> Acesso em 06 de set. 2018 .

OMC. CE - Hormônios (1996). DS26: Comunidades Européias - Medidas que afetam carne e produtos cárneos (hormônios). Disponível em:<https://www.wto.org/spanish/tratop_s/dispu_s/cases_s/ds26_s.htm> Acesso em 06 de set. 2018.

OMC. Estados Unidos - Jogos de azar (2003). DS285: Estados Unidos - Medidas que afetam a oferta transfronteiriça de serviços de apostas e apostas. Disponível em:< https://www.wto.org/spanish/tratop_s/dispu_s/cases_s/ds285_s.htm> Acesso em 06 de set. 2018.

OMC. Estados Unidos - Camarões. DS58: Proibição à importação de camarões e de certos produtos derivados de camarões. Disponível em: <https://www.wto.org/spanish/tratop_s/dispu_s/cases_s/ds58_s.htm> Acesso em 06 de set. 2018.

ONU (1980). Convenção de Viena sobre o Direito dos Tratados. Viena, 23 de maio de 1969. Disponível 
<http://www.oas.org/XXXVGA/espanol/doc_referencia/Convencion_Viena.pdf> Acesso em 01 de set. 2018.

PATRIOTA, Erika Almeida Watanabe. Bens Ambientais, OMC e o Brasil. Brasília : FUNAG, 2013.

PIFFER, Carla. Comércio Internacional e Meio Ambiente: a Organização Mundial do Comércio como locus de Governança Ambiental. Revista Veredas do Direito. Belo Horizonte, V. 8 ž no 15, jan./jun. 2011, p. 111-132.

SACHS, Ignacy. Desenvolvimento includente, sustentável, sustentado. Editora Garamond, 2004.

SEN, Amartya. Desenvolvimento como liberdade. Editora Companhia das Letras, 2013.

RAUCCI, Regina Maciel. Do DesenvolvimentoSustentável às Exceçõesnão-comerciais do Tratado de Marraqueche: o Meio Ambiente e a OMC. 2010. Trabalho de conclusão de curso (Mestrado em Direito). Franca: Universidade Estadual Paulista Júlio de MesquitaFilho, 2010. Disponível em: < https://www.franca.unesp.br/Home/sgfdfg/reginamaciel.pdf> Acesso em 05 de set. de 2018.

REALE, Paulo de Tarso. A Organização Mundial de Comércio e a Questão Ambiental. Porto Alegre: UFRGS, 2010.

RIBEIRO, Roberta Solis. Comércio Internacional e Meio Ambiente: Interaçõessob a Perspectiva da Organização Mundial de Comércio. 2008. Trabalho de conclusão de curso (Especialista em Relações Internacionais), Universidade de Brasília, Brasília, 2008. Disponível em: < http://bdm.unb.br/bitstream/10483/1104/1/2008_RobertaSolisRibeiro.pdf>. Acesso em 03 de set. de 2018.

THORSTENSEN, Vera Helena; OLIVEIRA, Luciana. O Sistema de Solução de Controvérsias da OMC: uma primeira leitura. 2014. Disponível em: < https://bibliotecadigital.fgv.br/dspace/bitstream/handle/10438/15952/500131.pdf > . Acesso em 06 de set. de 2018.

THORSTENSEN, Vera. OMC-Organização Mundial do Comércio: as Regras do Comércio Internacional e a Nova Rodada de Negociações Multilaterais. $2^{\mathrm{a}}$ Ed. São Paulo: Aduaneiras, 2001.

, Vera. A OMC e as negociações sobre comércio, meio ambiente e padrõessociais.

Rev. Bras. Polít. Int. 41 (2): 29-58, 1998.

WT/MIN(96)/DEC (1996). Conferência Ministerial realizada em Singapura em 9 e 13 de Dezembro de 1996. Disponível em:<https://www.wto.org/spanish/thewto_s/minist_s/min96_s/min96_s.htm Acesso em 05 de set. de 2018 .

Rev. de Direito, Economia e Desenvolvimento Sustentável| e-ISSN: 2526-0057| Porto Alegre | v. 4 | n. 2 | p. 76 - 92 | Jul/Dez. 